\section{Eficacia de la vacuna contra la influenza y su impacto en las inequidades en salud}

En la década de 1990, la vacunación contra la influenza se encontraba entre las intervenciones sanitarias dirigidas a los adultos mayores más efectivas en función del costo y su aplicación se consideraba una medida indispensable en la atención de este sensible grupo de la población. Por otra parte, se ha establecido que la implementación de programas sanitarios, como la vacunación, puede llevar a un aumento en las inequidades en salud y se ha empleado la hipótesis de la equidad inversa para explicar ese efecto. Según esta hipótesis, las mejoras generales logradas mediante estas intervenciones alcanzan primero a los grupos sociales de mejor situación económica que a los más pobres, lo que aumenta la brecha de desigualdades.

La vacunación de los ancianos que viven en la comunidad tiene detractores. Algunos autores consideran que la mayor efectividad se logra en adultos mayores que permanecen en instituciones - como hogares de ancianos- por largos períodos de tiempo, a pesar de reconocer su efecto benéfico general en cuanto a evitar complicaciones secundarias y hospitalizaciones y reducir el riesgo de muerte. Sin embargo, la información disponible proviene principalmente de estudios realizados en países templados. En los países tropicales y de clima cálido no se ha establecido totalmente la magnitud de la carga de la influenza y no se ha estudiado adecuadamente la eficacia de la vacuna contra esta enfermedad.

En este estudio se evaluó la eficacia de la vacunación contra la influenza en personas de 65 años de edad o más de la ciudad de São Paulo, Brasil. Para ello se estimó la reducción de la mortalidad atribuible a esta enfermedad antes de la implementación de las campañas de vacunación (1993-1997) y después (1998-2002), cuando la vacunación abarcaba más de $60 \%$ de los adultos mayores. Además, se evaluó la magnitud de las diferencias en la mortalidad de las diferentes zonas de la ciudad.

Se observó una notable reducción en la mortalidad por neumonía e influenza en las personas de 65 años o más durante el período posterior a la vacunación. El número de hospitalizaciones por neumonía se redujo en $19,1 \%$ en ese grupo de edad en las temporadas invernales (de junio a agosto) en el período 1999-2001, en comparación con los años que precedieron a la vacunación. No se encontró reducción alguna en el número de hospitalizaciones o de muertes por neumonía e influenza en los grupos de personas menores de 65 años.

La reducción proporcional en la mortalidad por neumonía e influenza en cada distrito de la ciudad permitió identificar un patrón geográfico. Las zonas centrales de la ciudad -ocupadas por familias de mejor situación socioeconómica- mostraron una menor reducción, mientras que las zonas con reducciones medias o elevadas en la mortalidad por estas causas se caracterizaban por una mayor pobreza. Estos resultados indican que los segmentos de la población que vivían en áreas más pobres de la ciudad se beneficiaron más con la vacunación que los que vivían en las zonas más ricas.

A pesar de que las tasas de vacunación no se estimaron por zonas y que el bajo número de muertes por neumonía e influenza en las personas de 65 años o más en cada distrito no permitió evaluar los cambios a ese nivel, estos resultados respaldan la hipótesis de que la vacunación influyó positivamente en el perfil de equidad de la ciudad.

De esta forma, se encontró una asociación significativa entre la vacunación contra la influenza en personas de 65 años o más y la reducción en la mortalidad general y específica por neumonía e influenza y con la reducción de las inequidades en salud. Se puede revertir la hipótesis de la equidad inversa si existe la voluntad política y el compromiso de implementar intervenciones sanitarias con acceso universal, efectivo y expedito. Por su efectividad general y su contribución en la reducción de las inequidades en salud, la vacunación contra la influenza en São Paulo demostró ser una estrategia factible para promover al mismo tiempo una mejor salud y una mayor justicia social. (Ferreira Antunes JL, Alves Waldman E, Borrell C, Paiva TM. Effectiveness of influenza vaccination and its impact on health inequalities. Int J Epidemiol. Advance Access published October 31, 2007.) 